\title{
MTA1 gene silencing inhibits invasion and alters the microRNA expression profile of human lung cancer cells
}

\author{
XIAOXIA ZHU ${ }^{1 *}$, XIAO ZHANG ${ }^{1 *}$, HAOFEI WANG ${ }^{2 *}$, QINGCUI SONG $^{4 *}$, GONG ZHANG $^{4}$, \\ LEI YANG ${ }^{3}$, JIAN GENG ${ }^{3}$, XIANGZHAO LI $^{3}$, YAWEI YUAN ${ }^{1}$ and LONGHUA CHEN ${ }^{1}$ \\ Departments of ${ }^{1}$ Radiation Oncology, ${ }^{2}$ Cardiothoracic Surgery, ${ }^{3}$ Pathology, Nanfang Hospital, and \\ ${ }^{4}$ Cancer Research Institute, Key Laboratory for Transcriptomics and Proteomics of Human Fatal Diseases, \\ Southern Medical University, Guangzhou, Guangdong 510515, P.R. China
}

Received January 26, 2012; Accepted March 8, 2012

DOI: $10.3892 /$ or.2012.1770

\begin{abstract}
Metastasis-associated gene 1 (MTA1) is involved in the carcinogenesis and metastasis of many human carcinomas. However, its exact role in non-small cell lung cancer (NSCLC) is still unclear. Using immunohistochemistry analysis, we recently identified MTA1 to be associated with the progression of NSCLC. Here, we carried out further analysis on the effect of MTA1 knockdown in an NSCLC cell line on cell functions and the global microRNA (miRNA) expression profile. We succeeded in establishing the MTA1 knockdown NSCLC cell line using RNA interference (RNAi), and found that the silencing of MTA1 resulted in the effective inhibition of the invasive ability of NSCLC cells, but not of the cell growth in vitro. We performed an miRNA microarray analysis and demonstrated for the first time that MTA1 knockdown significantly changed the expression of some miRNAs in NSCLC cells. Among them, some have a well-characterized association with cancer progression, e.g. miR-125b, miR-210, miR-103, miR-194 and miR-500. In summary, it is evident from our results that MTA1 functions in regulating the invasive phenotype of lung cancer cells and this regulation may be through altered miRNA expression. The interaction between MTA1 and the miRNAs which contributes to lung cancer is worthy of further investigation.
\end{abstract}

Correspondence to: Dr Yawei Yuan or Dr Longhua Chen, Department of Radiation Oncology, Nanfang Hospital, Southern Medical University, Guangzhou, Guangdong 510515, P.R. China

E-mail: yuanyaweifl@126.com

E-mail: chenlonghuafl01@126.com

*Contributed equally

Key words: metastasis-associated gene 1, non-small cell lung cancer, invasiveness, cell migration, microRNA

\section{Introduction}

Metastasis-associated gene 1 (MTA1), originally identified through differential screening of a cDNA library from rat metastatic breast tumors (1), is the founding member of the MTA family of coregulators in transcriptional programs (2), and an integral part of the nucleosome remodeling and histone deacetylation (NuRD) complex. The role of MTA1 in tumor progression has aroused wide concern. It has been found to be upregulated in human tumors (3), and to be associated with carcinogenesis and metastasis of many types of cancer, such as breast cancer, hepatocellular carcinoma, and B cell lymphomas (4-6).

In our previous study, we detected MTA1 protein expression in NSCLC tissue specimens. We found that MTA1 overexpression was significantly correlated with tumor progression and poor prognosis of NSCLC (7). However, there is still lack of direct evidence that MTA1 is responsible for aggressive phenotypes of NSCLC, and the underlying mechanism is unclear as well.

microRNAs (miRNAs) are a class of endogenous, small (21-23 nucleotides in length), non-coding RNAs. They act by regulating the expression of their target genes by perfect or imperfect complementarity, causing either mRNA molecule degradation or translational inhibition (8). Aberrant expression of miRNA is widespread in human cancers. Recent evidence indicates that miRNAs can function as either oncogenes or tumor suppressors $(9,10)$, and play a regulatory role in the metastatic process of lung cancer (11-13). However, many cancer-related miRNAs are still unknown, and the mechanism of the miRNA involvement in tumor metastasis remains unclear. In addition, reports on the regulation of miRNA expression are scarce.

In this study, we established a stable MTA1 silencing NSCLC cell line with RNA interference (RNAi) technology, and found that silencing of MTA1 can inhibit cell invasion and migration, but has little effect on cell proliferation. We further examined the changes of the miRNA expression profile in human NSCLC 95D cells after MTA1 silencing, and the microarray results were confirmed by quantitative real-time 
polymerase chain reaction analysis (qRT-PCR). Our results suggest that miRNAs may mediate, at least in part, the regulation of the metastatic phenotype of NSCLC by MTA1.

\section{Materials and methods}

Cell culture. HBE, H460, A549, and 95D cell lines grown in RPMI medium (Gibco, Grand Island, NY) supplemented with $10 \%$ fetal bovine serum were cultured in a humidified atmosphere in a $5 \% \mathrm{CO}_{2}$ incubator at $37^{\circ} \mathrm{C}$.

Stable transfection. The 95D cell line, which showed the maximum MTA1 expression among the cell lines examined, was selected for the MTA1 gene silencing study. Three human shRNA sequences targeting MTA1 were cloned into the pLVTHM plasmid containing the EGFP gene (Tronolab, Lausanne, Switzerland) to generate pLVTHM-MTA1-RNAi(s); the sequences were MTA1-sil\#: sense, 5'-CGCGTCCCCGG AGAGATTCGAGTAGGAAACTTCAAGAGAGTTTCCTA CTCGAATCTCTCCTTTTTGGAAAT-3'; MTA1-si2\#: sense, 5'-CGCGTCCCCGCAGCAGAAACGCTTGAAAG CTTCAAGCGTTTCTGCTGCTTTTTGGAAAT-3' and MTA1-si3\#, sense, 5'-CGCGTCCCCAAGACCCTGCTGG CAGATAAATTCAAGAGATTTATCTGCCAGCAGGGTC TTTTTTTGGAAAT-3' (synthesized by Invitrogen). A scrambled siRNA (5'-GACGACGATAAGGGATCCTGA-3'), which has no homology with the mammalian mRNA sequences, was inserted into the pLVTHM vector as described above to generate pLVTHM-CTL-si. Cells were all transfected with $3 \mu \mathrm{g}$ of plasmids (pLVTHM-MTA1-si1\#, or pLVTHM-CTLsi), or empty pLVTHM vector using Lipofectamine 2000 (Invitrogen, Carlsbad, CA) according to the manufacturer's protocol. The independent colonies resistant to neomycin were chosen and subcultured for 14 days in G418 selection. These three cell lines were named as 95D/MTA1-sil\#, 95D/CTL-si, and $95 \mathrm{D} / \mathrm{NC}$.

Western blot analysis. Total protein was extracted from cells using RIPA kit (Pierce, USA). Protein was electrophoresed on a polyacrylamide gel and transferred to Hybond-C nitrocellulose membranes. The membranes was incubated with anti-MTA1 (Abcam, Cambridge, MA, USA), anti- $\beta$-actin (Santa Cruz Biotechnology, Santa Cruz, CA, USA) at 1:1,500 dilution at $37^{\circ} \mathrm{C}$ for $2 \mathrm{~h}$, and then with peroxidise-conjugated goat anti-mouse IgG (Beijing Biosynthesis Biotech, Co., Ltd., Beijing, China) at 1:2,000 at room temperature for $1 \mathrm{~h}$. $\beta$-actin was used as an internal control. Proteins were visualized using enhanced chemiluminescence (ECL) methods. Membranes were washed three times and then exposed to X-ray film.

Cell invasion assay. For invasion assays, $1 \times 10^{4}$ cells in serumfree media were seeded into the upper chambers of a 24-well BioCoat Matrigel invasion chamber (BD Biosciences, Bedford, MA, USA) with an $8-\mu \mathrm{m}$ pore polycarbonate membrane coated with Matrigel. Medium with 10\% FBS was added to the lower chambers as a chemoattractant. After $24 \mathrm{~h}$ of incubation, cells remaining on the upper surface of the membrane were removed with a cotton swab, and cells that invaded through the membrane filter were fixed with $4 \%$ paraformaldehyde, stained by haematoxylin and eosin, and photographed under a microscope (Olympus BX40 with a DP70 digital camera). The number of invading cells was manually counted per highpower field for each condition (five fields on each membrane were randomly selected).

Wound healing assay. Cells were grown to confluence in a 6-well plate. Artificial wound tracks were created by scraping confluent cell monolayers with a pipette tip. After removal of the detached cells by gently washing with PBS, the cells were fed with fresh complete medium and incubated over time to allow cells to migrate into the open area. The ability of the cells to migrate into the wound area was assessed at 1,24 and $48 \mathrm{~h}$ after scratching by comparing the pixels of the wound tracks in micrographs of three randomly selected wounded areas.

Cell proliferation assay and colony formation assay. The proliferation of transfected cells was measured by the MTT assay. Ten microliters of MTT $(5 \mathrm{mg} / \mathrm{ml})$ was added to each culture volume of $100 \mu \mathrm{l}$, which contained $1 \times 10^{3}$ viable cells per well. After an additional incubation for $4 \mathrm{~h}$, the resulting formazan was dissolved in $100 \mu 1$ isopropanol with $40 \mathrm{mM}$ hydrochloric acid. Spectrophotometric absorbance at $570 \mathrm{~nm}$ (for formazan dye) was measured, along with absorbance at $630 \mathrm{~nm}$ as a reference. To assay colony formation, a total of 1,000 cells were plated onto a $100-\mathrm{mm}$ dish and cultured for 14 days in complete DMEM supplemented with blasticidine. The colonies were fixed with $100 \%$ methanol $2 \times 10 \mathrm{~min}$, stained with $0.2 \%$ crystal violet in $75 \%$ methanol for $30 \mathrm{~min}$, and then visualized and counted.

Flow cytometry analysis. Exponentially growing cells were trypsinized, and single-cell suspensions containing $1 \times 10^{6}$ cells were fixed in $70 \%$ cold ethanol at $4^{\circ} \mathrm{C}$. The cell cycle was monitored using propidium iodide (PI) staining of nuclei. The fluorescence of DNA-bound PI in cells was measured with a FACScan flow cytometer (BD Biosciences), and the results were analyzed with ModFit3.0 software (Verity Software House, Topsham, ME, USA).

miRNA microarray analysis. Total RNA samples extracted from two cell lines (95D/MTA1-si1\# and 95D/NC) were analyzed by CapitalBio (CapitalBio Corp., Beijing, China) for miRNA microarray experiments. Procedures were performed as described in detail (http://www.capitalbio.com). Briefly, total RNA was extracted with TRIzol ${ }^{\circledR}$ reagent. Small-sized RNA was isolated using an miRNA isolation kit (Ambion, Inc.). Fluorescein-labeled miRNAs were then hybridized on each miRNA microarray containing 509 probes in triplicate, corresponding to 435 human (including 122 predicted miRNAs), 261 mouse and 196 rat miRNAs, to determine differential expression between the cell lines. Every sample was assayed in triplicate. Arrays were scanned with a LuxScan 10K-A laser confocal scanner and images were analyzed using LuxScan3.0 software (CapitalBio Corp.). Expression data in different chips were median centered using global median normalization. Differentially expressed miRNAs were identified by SAM, version 2.1 (Stanford University, Stanford, CA, USA). We identified genes with a false discovery rate of $<5 \%$ and an absolute fold change of $\geq 2.0$. 
Table I. List of primers for qRT-PCR analysis of miRNAs (fold-change $>2$ ).

\begin{tabular}{|c|c|c|}
\hline Gene & RT primers & Sequence of PCR primers ( $\left.5^{\prime}-3^{\prime}\right)$ \\
\hline U6 & 5'-AACGCTTCACGAATTTGCGT-3' & $\begin{array}{l}\text { F: CTCGCTTCGGCAGCACA } \\
\text { R: AACGCTTCACGAATTTGCGT }\end{array}$ \\
\hline hsa-miR-103 & 5'-extension-CATAGCC-3' & F: ACACTCCAGCTGGGAGCAGCATTGT ACAGGGC \\
\hline hsa-miR-125b & 5'-extension-CACAAGTT-3' & F: ACACTCCAGCTGGGTCCCTGAGACCCTAACT \\
\hline hsa-miR-194 & 5'-extension-CCACATG-3' & F:ACACTCCAGCTGGGTGTAACAGCAACTCCATGTG \\
\hline hsa-miR-210 & 5'-extension-CAGCCGC-3' & F: ACACTCCAGCTGGGCTGTGCGTGTGACAGCGG \\
\hline hsa-miR-500 & 5'-extension-CTCACCC-3' & F: ACACTCCAGCTGGGTAATCCTTGCTACCTGGG \\
\hline $\begin{array}{l}\text { hsa-miR-744 } \\
\text { miR universal }\end{array}$ & 5'-extension-GCTGTTA-3' & $\begin{array}{l}\text { F: ACACTCCAGCTGGGTGCGGGGCTAGGGCTAAC } \\
\text { R: CTCAACTGGTGTCGTGGA }\end{array}$ \\
\hline
\end{tabular}

The sequence of the 5'-extension for the RT primers is 5'-CTCAACTGGTGTCGTGGAGTCGGCAATTCAGTTGAGT-3'.

A

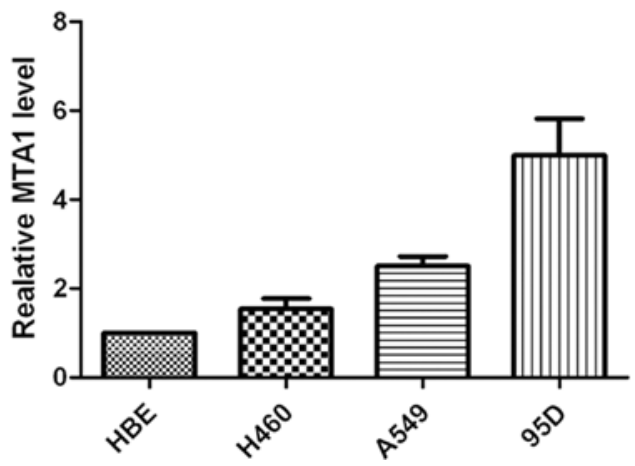

B

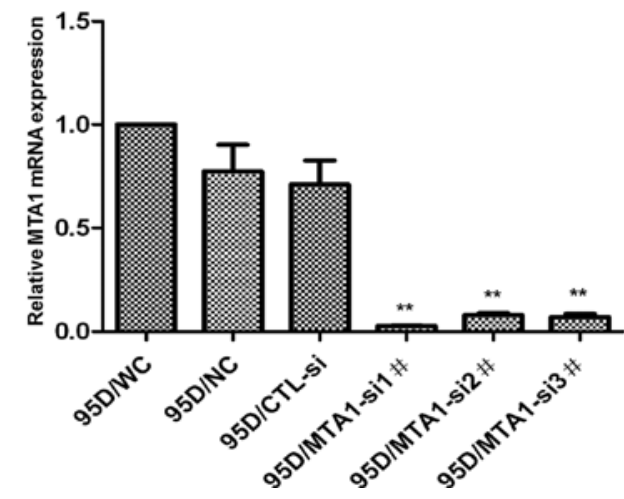

C

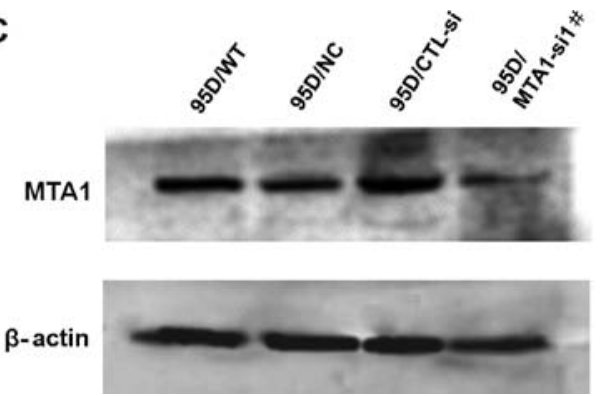

Figure 1. Expression of MTA1 in lung cancer cell lines and knockdown of MTA1 by siRNA. (A) qRT-PCR showing MTA1 mRNA levels in three lung cancer cell lines and one normal cell line. Data are expressed as a fold change relative to control (control is HBE). (B) qRT-PCR analysis of MTA1 mRNA expression in 95D/WT, 95D/NC, 95D/CTL-si and MTA1 knockdown cell lines (95D/MTA1-si1\#, 95D/MTA1-si2\# and 95D/MTA1-si3\#). Values are given as mean $\pm \mathrm{SD}$ of three experiments. ${ }^{* *} \mathrm{P}<0.01$ as compared to $95 \mathrm{D} / \mathrm{WT}$. (C) Western blot analysis of MTA1 protein expression in 95D/WT, 95D/NC 95D/CTL-si and 95D/MTA1-si1\# stable cell lines.
Quantitative real-time polymerase chain reaction analysis. Analysis for MTA1 mRNA was carried out as previously described (7). The primer sequences used in RT-PCR were: MTA1, forward: 5'-AGCTACGAGCAGCACAACGGGGT-3' and reverse: 5'-CACGCTTGGTTTCCGAGGAT-3'; GADPH, forward: 5'-TCTTCGCTTTGTCCTTTCGT-3' and reverse: 5'-TGCTGTAGCCAAATTCGTTG-3'.

To confirm the microarray results, total RNA was isolated as above. Reverse transcription was performed with specific primers (Table I) for hsa-miR-125b, hsa-miR-155, hsa-miR-210, hsa-miR-103, hsa-miR-194, hsa-miR-500 and hsa-miR-744, and U6 was used as an internal control. qRT-PCR was carried out using the Rotor-Gene 3000 Real-Time PCR system. The PCR reaction mixture with a total volume $25 \mu 1$ contained $25 \mathrm{ng}$ cDNA, $800 \mathrm{nM}$ of each specific primer (Table I) and $0.25 \mathrm{X}$ SYBR-Green (diluted from 1000X SYBR-Green, Molecular Probes). After denaturing at $95^{\circ} \mathrm{C}$ for $5 \mathrm{~min}$, the reactions were amplified for $15 \mathrm{sec}$ at $95^{\circ} \mathrm{C}$ and $30 \mathrm{sec}$ at $65^{\circ} \mathrm{C}$ and $20 \mathrm{sec}$ at $72^{\circ} \mathrm{C}$ for 40 cycles. The thermal denaturation protocol was run at the end of the PCR to determine the number of products that were present in the reaction. The relative amount of each miRNA to U6 RNA was calculated using the $2^{-\Delta \Delta C t}$, where $\mathrm{Ct}$ is the number of cycles at which amplification reaches a threshold, determined by SDS software v1.2 (Applied Biosystems Inc.).

Statistical analysis. Data analysis was performed with the SPSS 13.0 statistical software. P-values were generated by the Student's t-test for qRT-PCR data, migration assays and colony formation assays, and by two-way ANOVA for the cell proliferation assays. All experiments were performed in triplicate.

\section{Results}

Expression of MTA1 in human lung cancer cell lines and siRNA-mediated silence. First, we examined MTA1 mRNA expression in three lung cancer cell lines (H460, A549, and 95D) and the normal cell line HBE (human lung bronchial epithelium) by qRT-PCR. MTA1 was detected in all cell lines evaluated, with 95D cells expressing the highest levels (Fig. 1A). Therefore, 95D cells were selected as the model for the subsequent function studies. 


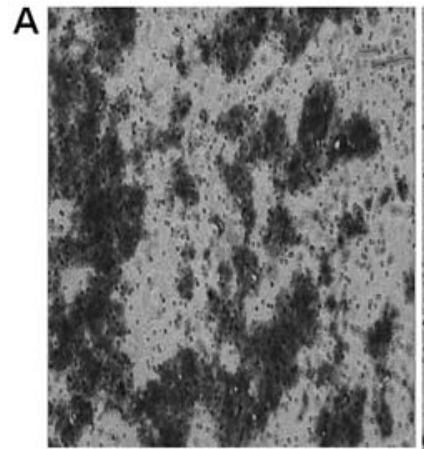

$95 \mathrm{D} / \mathrm{CTL}-\mathrm{si}$

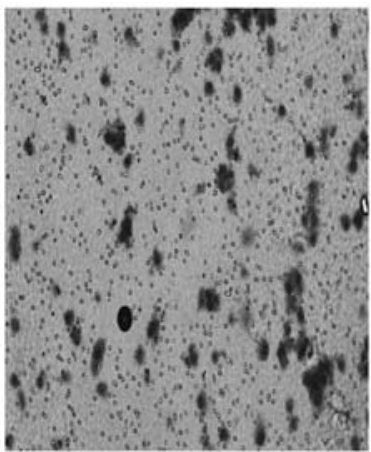

95 D / M T A $1-$ s i 1 \#

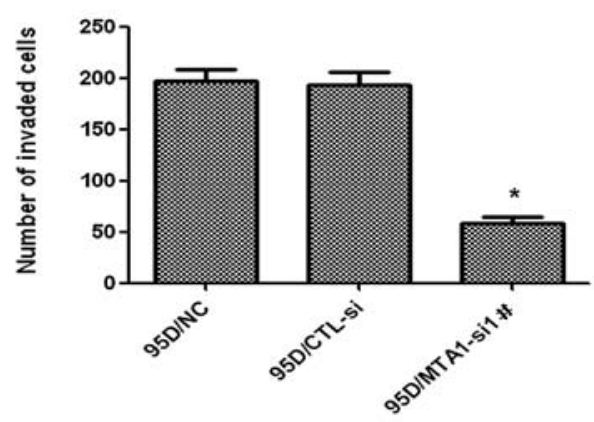

B

$\mathrm{Oh}$
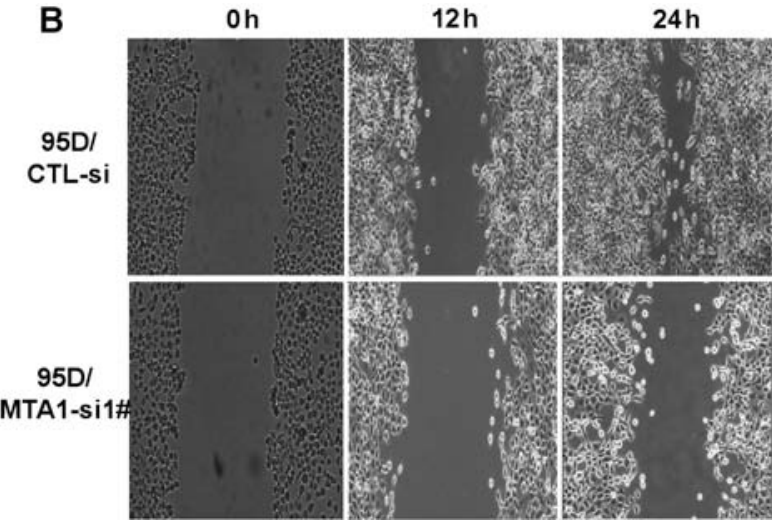

Figure 2. Silencing of MTA1 gene inhibits the migration and invasion of lung cancer cells. (A) Cell invasion assay invasion cells were fixed and stained, and representative fields were photographed. For quantification, the cells were counted in 5 random fields under a light microscope (x200). Triplicate assays were performed for each group of cells in invasion assays, and the results are expressed as means \pm SD $\left({ }^{*} \mathrm{P}<0.05\right)$. (B) Summary of wound-healing assay associated with tumor cell migration. Phase-contrast micrographs of the scratched monolayer of 95D/NC, 95D/CTL-si and 95D/MTA1-si1\# cells at 0,12 and $24 \mathrm{~h}$ after scratching.

The expression of MTA1 mRNA was significantly decreased in the cells handled with the three human shRNA sequences targeting MTA1 compared to control. Furthermore, MTA1-sil\# was the most effective silencing sequence (Fig. 1B). Western blot analysis showed that expression of MTA1 protein also decreased markedly in the MTA1 knockdown stable cell line 95D/MTA1-si1\# (Fig. 1C).

MTA1 gene silencing inhibits 95D cell invasion and migration in vitro. We next determined the ability of 95D/MTA1-si1\#, 95D/CTL-si, and 95D/NC cells to invade through extracellular matrix (ECM) in a Boyden chamber invasion assay. As shown in Fig. 2A, the number of 95D/MTA1-si1\# cells

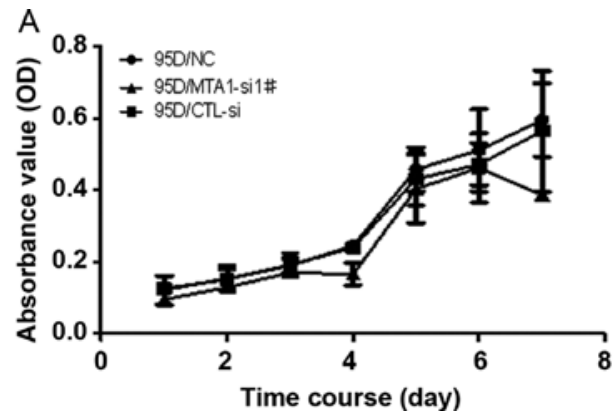

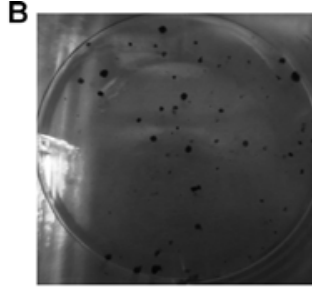

95D/CTL-si

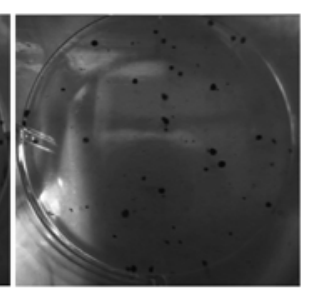

95D/MTA1-si1\#
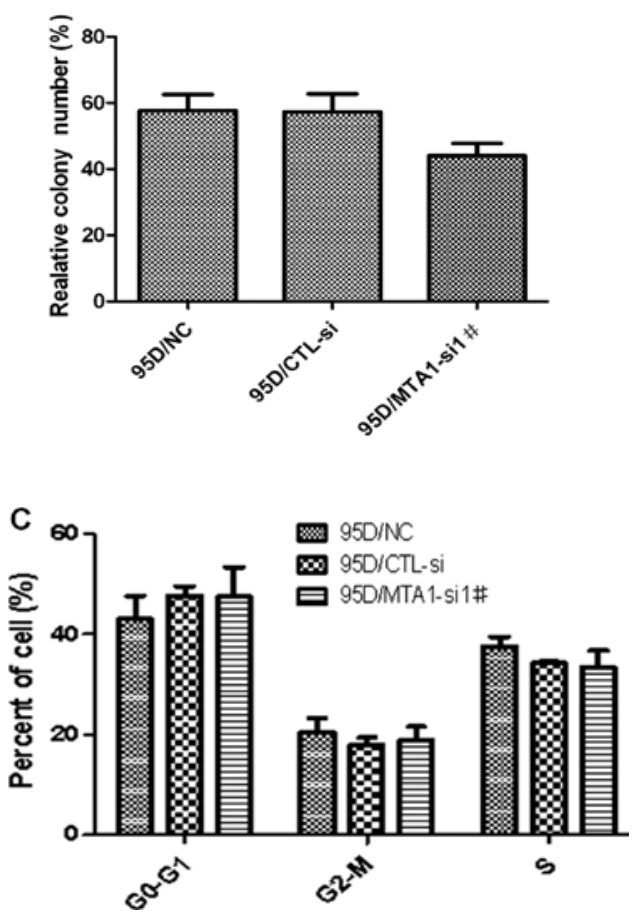

Figure 3. Silencing of the MTA1 gene has little influence on the growth of lung cancer cells. (A) MTT proliferation assay. (B) Colony formation assay. (C) Flow cytometry analysis. All results were reproducible in three independent experiments $(\mathrm{P}>0.05)$.

invading through the membrane was significantly lower than that of $95 \mathrm{D} / \mathrm{NC}$ cells $(60.00 \pm 6.25$ vs. $195.00 \pm 10.83, \mathrm{P}<0.001)$. It appears that MTA1 affects lung cancer cell invasion.

We also used an in vitro wound healing assay to determine the effect of MTA1 silencing on 95D cell migration. Fig. 2B shows that the healing speed was slower and that the gaps were wider in 95D/MTA1-sil\# cells at each time point than in the 95D/CTL-si cells. These data indicate that MTA1 promoted 95D cell migration.

Silencing of MTA1 gene has little influence on the growth of $95 \mathrm{D}$ cells. Because downregulation of MTA1 has been 

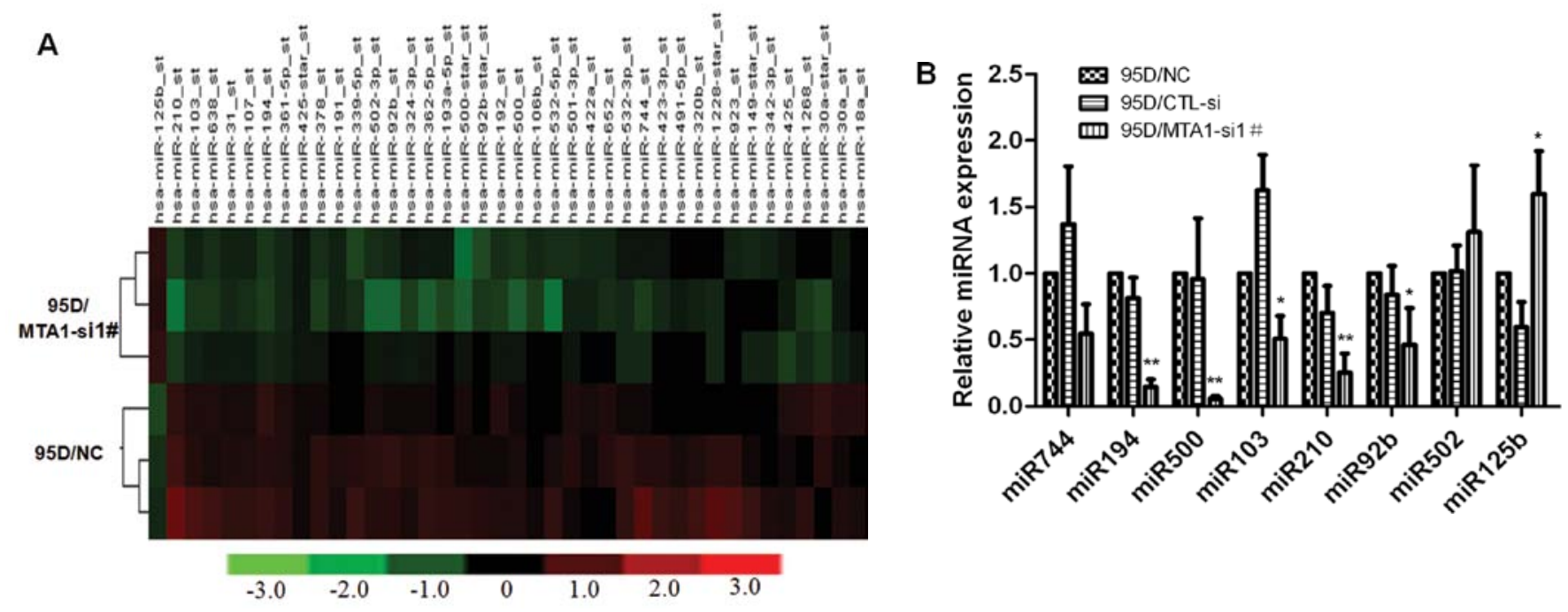

Figure 4. Effect of MTA1 gene silencing on miRNA expression profile of 95D cells. (A) Change of miRNA expression profiling of 95D cancer cells determined by microarray. Heat map of hierarchical clustering of differentially expressed miRNA in 95D/MTA1-si and 95D/NC. Red denotes high expression levels, whereas green depicts low expression levels. (B) The expression of miRNAs were verified using qRT-PCR. Values are presented as mean \pm SD of three experiments $\left({ }^{*} \mathrm{P}<0.05,{ }^{* *} \mathrm{P}<0.01\right.$ as compared to $\left.95 \mathrm{D} / \mathrm{NC}\right)$.

shown to inhibit breast cancer cell growth (14), we sought to examine whether silencing of MTA1 could influence 95D cell growth. Using a colony formation assay, we found that there was no significant difference in the ability to form colonies between 95D/MTA1-si1\# and 95D/NC cells (Fig. 3B). The cell proliferation assay also showed little growth inhibition in $95 \mathrm{D} /$ MTA1-si cells compared to 95D/NC cells (Fig. 3A). These data indicate that MTA1 silencing has little effect on the growth and clonogenic capacity of 95D cells. Consistent with this result, we did not observe a difference in cell cycle progression between 95D/MTA1-si1\# and 95D/NC cells (Fig. 3C).

Effect of MTA1 gene silencing on the miRNA expression profile of $95 \mathrm{D}$ cells. To identify the effect of MTA1 gene silencing on the miRNA expression in 95D cells, a miRNA microarray capable of measuring expression of 509 miRNAs was used to analyze the miRNA profile changes between 95D/MTA1-si and 95D/NC cell lines. The microarray analysis demonstrated that 40 miRNA genes exhibited significant differential expression (false discovery rate $<5 \%$ ). The relative expression of these miRNAs is presented as a heat map in Fig. 4A. Of the screened miRNAs, we only identified 6 genes with an absolute fold change $>2.0$. miR-125b was significantly upregulated with 2.156-fold increase in 95D/MTA1-si1\# cells compared with 95D/NC cells. Contrarily, miR-210, miR-500, miR-194, miR-103 and miR-744 were significantly downregulated in 95D/ MTA1-si1\# cells, with 0.290, 0.466, 0.431, 0.498, and 0.496-fold decreases, respectively, compared with $95 \mathrm{D} / \mathrm{NC}$ cells.

In order to exclude possibilities of false-positive results coming from miRNA microarray analysis, we performed quantitative RT-PCR analysis to verify the expression of miR-125b, miR-210, miR-500, miR-194, miR-103 and miR-744. Quantitative reverse transcription-polymerase chain reaction (qRT-PCR) results revealed that miR-125b was upregulated, while miR-210, miR-500, miR-194 and miR-103 were downregulated in the 95D/MTA1-sil\# cells, which was in accordance with the results from the miRNA microarray (Fig. 4B).

\section{Discussion}

As outlined in the introduction, the deregulation of MTA1 has been found in various human malignancies. Our previous study also found that MTA1 overexpression was significantly correlated with tumor progression and poor prognosis of NSCLC (7). However, the exact function of MTA1 in the tumor cell biology of lung cancer has not been thoroughly investigated. To address this issue, we evaluated MTA1 expression with regard to possible direct correlations with cell growth and invasion of lung cancer cells.

The functions of MTA1 on tumorigenesis and cell cycle progression are still unclear. In the present study, our data did not reveal that the silencing of MTA1 had any detectable effect on proliferation, colony formation, or cell cycle progression of 95D cells. This observation is in contrast to results of the study by Jiang et al (14). However, the divergent findings about the effect of MTA1 on tumor growth and cell cycle progression have been previously reported (15-18). While the reasons of this apparent discrepancy are currently unknown, we presumed that MTA1 could function as an activator or repressor on cell growth in a cellular context-dependent manner through influencing the balance between different genes relating to growth.

Tumor metastasis consists of multiple sequential steps regulated by various genes. The breakdown of the base membrane is considered as the initial and one of the most characteristic steps during the cascade of metastasis. In this study, downregulation of MTA1 in 95D cells by MTA1 gene silencing showed significantly decreased migration and invasion. These in vitro studies provide evidence that MTA1 may play important roles in lung cancer development. Our results are consistent with the in vitro studies on esophageal carcinoma cells and melanoma cells performed by Qian et al $(19,20)$. MTA1 downregulation greatly reversed the malignant phenotypes of cancer cells.

However, to date, the molecular mechanisms by which MTA1 enhances the metastatic potential of tumor cells are still poorly understood. Only a few reports suggest that MTA1 
may promote tumor progression by participating in chromatin remodeling $(21,22)$, hypoxia signaling pathway $(23)$, or the epithelial-mesenchymal transition pathway (24).

miRNAs are small non-coding RNAs and have been implicated in the pathology of various diseases, including lung cancer. Both MTA1 and miRNAs play a regulatory role in the metastatic process of lung cancer. We thus sought to determine whether MTA1 is involved in lung cancer metastasis through regulating miRNA expression in lung cancer cells.

In this study, we detected that a number of miRNAs were altered upon MTA1 knockdown by employing miRNA microarray. Among the miRNAs with a fold change $>2$, we found that miR-125b was upregulated by MTA1 knockdown. It has been shown that miR-125b functions as a tumor suppressor in lung cancer (25), oral squamous cell carcinoma (26), prostate cancer (27) and bladder cancer (28). miR-125b was significantly correlated with good prognosis of liver cancer (29). Transfecting oral squamous cell carcinoma cells with exogenous miR-125b significantly reduced cell proliferation (26). miR-125b was found to be underexpressed in metastatic breast cancer and metastatic liver cancer compared with their primary tumors $(30,31)$.

On the other hand, miR-210, miR-194, miR-500 and miR-103 were found to be downregulated by MTA1 knockdown. According to the literature, miR-210 is involved in hypoxia signaling pathway and has been correlated with poor prognosis of breast cancer and pancreatic cancer $(32,33)$. miR-500 was found to be abundantly expressed in several human liver cancer cell lines, $45 \%$ of human hepatocellular carcinoma (HCC) tissue, and the sera of HCC patients (34). Furthermore, the presence of miR-500 has been associated with triple-negative breast cancer (35). High expression of miR-103 has been correlated with poor survival of esophageal cancer (36). However, the role of miR-194 in tumorigenesis is controversial. It was found to be upregulated in esophageal adenocarcinoma (37) and downregulated in squamous cell carcinoma of the tongue (38). A noticeable phenomenon is that miR-192 was verified to enhance colony suppression and cell cycle arrest, partially dependent on the presence of wild-type p53 (39). This may partially support our previous hypothesis that MTA1 could influence the balance between different genes relating to growth.

In summary, silencing of MTA1 can effectively inhibit cell invasion and migration, and greatly reversed the malignant phenotypes of lung cancer cells. Furthermore, MTA1 can regulate the expression of some miRNAs which have a wellcharacterized association with cancer progression, suggesting that MTA1 could be involved in lung cancer metastasis through regulating miRNA expression in lung cancer cells. Although this study is the first to uncover the silencing of MTA1 as an inhibitor for cell invasion and migration via regulating miRNA expression, the complicated interaction between MTA1 and the miRNAs contributing to lung cancer is worthy of further investigation.

\section{Acknowledgements}

The present sudy was supported by grants from the National Natural Science Foundation of China (no. 81001047/ H1615), the Educational Commission of Guangdong Province (no. LYM09037), and the Natural Science Foundation of Guangdong Province (no. 9151051501000035).

\section{References}

1. Toh Y, Pencil SD and Nicolson GL: A novel candidate metastasis-associated gene, mtal, differentially expressed in highly metastatic mammary adenocarcinoma cell line. J Biol Chem 269: 22958-22963, 1994.

2. Manavathi B, Singh K and Kumar R: MTA family of coregulators in nuclear receptor biology and pathology. Nucl Recept Signal 5: e010, 2007.

3. Hofer MD, Tapia C, Browne TJ, Mirlacher M, Sauter G and Rubin MA: Comprehensive analysis of the expression of the metastasis-associated gene 1 in human neoplastic tissue. Arch Pathol Lab Med 130: 989-996, 2006.

4. Bagheri-Yarmand R, Talukder AH, Wang RA, Vadlamudi RK and Kumar R: Metastasis-associated protein 1 deregulation causes inappropriate mammary gland development and tumorigenesis. Development 131: 3469-3479, 2004.

5. Yoo YG, Na TY, Seo HW, Seong JK, Park CK, Shin YK and Lee MO: Hepatitis B virus $\mathrm{X}$ protein induces the expression of MTA1 and HDAC1, which enhances hypoxia signaling in hepatocellular carcinoma cells. Oncogene 27: 3405-3413, 2008.

6. Bagheri-Yarmand R, Balasenthil S, Gururaj AE, et al: Metastasisassociated protein 1 transgenic mice: a new model of spontaneous B-cell lymphomas. Cancer Res 67: 7062-7067, 2007.

7. Zhu X, Guo Y, Li X, Ding Y and Chen L: Metastasis-associated protein 1 nuclear expression is associated with tumor progression and clinical Outcome in patients with non-small cell lung cancer. J Thorac Oncol 5: 1159-1166, 2010.

8. Bartel DP: MicroRNAs: genomics, biogenesis, mechanism, and function. Cell 116: 281-297, 2004.

9. Croce CM and Calin GA: MiRNAs, cancer, and stem cell division. Cell 122: 6-7, 2005.

10. Esquela-Kerscher A and Slack FJ: Oncomirs-microRNAs with a role in cancer. Nature Rev Cancer 6: 857-866, 2006.

11. Lee YS and Dutta A: The tumor suppressor microRNA let-7 represses the HMGA2 oncogene. Genes Dev 21: 1025-1030, 2007.

12. Hurteau GJ, Carlson JA, Spivack SD and Brock GJ: Overexpression of the microRNA hsa-miR-200c leads to reduced expression of transcription factor 8 and increased expression of E-cadherin. Cancer Res 67: 7972-7976, 2007.

13. Crawford M, Brawner E, Batte K, et al: MicroRNA-126 inhibits invasion in non-small cell lung carcinoma cell lines. Biochem Biophys Res Commun 373: 607-612, 2008.

14. Jiang Q, Zhang $H$ and Zhang P: shRNA-mediated gene silencing of MTA1 influenced on protein expression of ER alpha, MMP-9, cyclin D1 and invasiveness, proliferation in breast cancer cell lines MDA-MB-231 and MCF-7 in vitro. J Exp Clin Cancer Res 30: 60, 2011.

15. Nawa A, Nishimori K, Lin P, et al: Tumor metastasis-associated human MTA1 gene: its deduced protein sequence, localization, and association with breast cancer cell proliferation using antisense phosphorothioate oligonucleotides. J Cell Biochem 79: 202-212, 2000.

16. Mazumdar A, Wang RA, Mishra SK, et al: Transcriptional repression of oestrogen receptor by metastasis-associated protein 1 corepressor. Nat Cell Biol 3: 30-37, 2001.

17. Mahoney MG, Simpson A, Jost M, et al: Metastasis-associated protein (MTA)1 enhances migration, invasion, and anchorageindependent survival of immortalized human keratinocytes. Oncogene 21: 2161-2170, 2002.

18. Hofer MD, Menke A, Genze F, Gierschik P and Giehl K: Expression of MTA1 promotes motility and invasiveness of PANC-1 pancreatic carcinoma cells. Br J Cancer 90: 455-462, 2004.

19. Qian H, Yu J, Li Y, Wang H, Song C, Zhang X, Liang X, Fu M and Lin C:RNA interference of metastasis-associated gene 1 inhibits metastasis of B16F10 melanoma cells in a C57BL/6 mouse model. Biol Cell 99: 573-581, 2007.

20. Qian H, Lu N, Xue L, Liang X, et al: Reduced MTA1 expression by RNAi inhibits in vitro invasion and migration of esophageal squamous cell carcinoma cell line. Clin Exp Metastasis 22: 653-662, 2005

21. Molli PR, Singh RR, Lee SW and Kumar R: MTA1-mediated transcriptional repression of BRCA1 tumor suppressor gene. Oncogene 27: 1971-1980, 2008. 
22. Gururaj AE, Holm C, Landberg G and Kumar R: Breast canceramplified sequence 3, a target of metastasis-associated protein 1 , contributes to tamoxifen resistance in premenopausal patients with breast cancer. Cell Cycle 5: 1407-1410, 2006.

23. Yoo YG, Kong G and Lee MO: Metastasis-associated protein 1 enhances stability of hypoxia-inducible factor-1alpha protein by recruiting histone deacetylase 1. EMBO J 25: 1231-1241, 2006.

24. Mishra SK, Talukder AH, Gururaj AE, et al: Upstream determinants of estrogen receptor- $\alpha$ regulation of metastatic tumor antigen 3 pathway. J Biol Chem 279: 32709-32715, 2004.

25. Yamada H, Yanagisawa K, Tokumaru S, et al: Detailed characterization of a homozygously deleted region corresponding to a candidate tumor suppressor locus at 21q11-21 in human lung cancer. Genes Chromosomes Cancer 47: 810-818, 2008.

26. Henson BJ, Bhattacharjee S, O'Dee DM, Feingold E and Gollin SM: Decreased expression of miR-125b and miR-100 in oral cancer cells contributes to malignancy. Genes Chromosomes Cancer 48: 569-582, 2009.

27. Schaefer A, Jung M, Mollenkopf HJ, et al: Diagnostic and prognostic implications of microRNA profiling in prostate carcinoma. Int J Cancer 126: 1166-1176, 2010.

28. Ichimi T, Enokida H, Okuno Y, et al: Identification of novel microRNA targets based on microRNA signatures in bladder cancer. Int J Cancer 125: 345-352, 2009.

29. Li W, Xie L, He X, et al: Diagnostic and prognostic implications of microRNAs in human hepatocellular carcinoma. Int J Cancer 123: 1616-1622, 2008.

30. Baffa R, Fassan M, Volinia S, et al: MicroRNA expression profiling of human metastatic cancers identifies cancer gene targets. J Pathol 219: 214-221, 2009.
31. Budhu A, Jia HL, Forgues M, et al: Identification of metastasisrelated microRNAs in hepatocellular carcinoma. Hepatology 47: 897-907, 2008.

32. Camps C, Buffa FM, Colella S, et al: hsa-miR-210 is induced by hypoxia and is an independent prognostic factor in breast cancer. Clin Cancer Res 14: 1340-1348, 2008.

33. Greither T, Grochola LF, Udelnow A, Lautenschläger C, Würl P and Taubert H: Elevated expression of microRNAs 155, 203, 210 and 222 in pancreatic tumors is associated with poorer survival. Int J Cancer 126: 73-80, 2010.

34. Yamamoto Y, Kosaka N, Tanaka M, et al: MicroRNA-500 as a potential diagnostic marker for hepatocellular carcinoma. Biomarkers 14: 529-538, 2009.

35. Janssen EA, Slewa A, Gudlaugsson E, et al: Biologic profiling of lymph node negative breast cancers by means of microRNA expression. Mod Pathol 23: 1567-1576, 2010.

36. Guo Y, Chen Z, Zhang L, et al: Distinctive microRNA profiles relating to patient survival in esophageal squamous cell carcinoma. Cancer Res 68: 26-33, 2008.

37. Mathé EA, Nguyen GH, Bowman ED, et al: MicroRNA expression in squamous cell carcinoma and adenocarcinoma of the esophagus: associations with survival. Clin Cancer Res 15: 6192-6200, 2009.

38. Wong TS, Liu XB, Wong BY, Ng RW, Yuen AP and Wei WI: Mature miR-184 as potential oncogenic microRNA of squamous cell carcinoma of tongue. Clin Cancer Res 14: 2588-2592, 2008.

39. Braun CJ, Zhang X, Savelyeva I, et al: p53-Responsive micrornas 192 and 215 are capable of inducing cell cycle arrest. Cancer Res 68: 10094-10104, 2008. 